\title{
H1N1 influenza vaccine: Global access for a global problem
}

Published at www.cmaj.ca on June 18, 2009.

$\mathrm{M}$ ore than $90 \%$ of the world's capacity to manufacture influenza vaccines is concentrated in Europe and North America. Pressure to protect one's own citizens will be intense during any pandemic. If any of the countries where these plants are located choose to nationalize the companies making the vaccine or to stop the vaccine from crossing their borders, the critical vaccine supply line will be choked. Ironically, the negative consequences of any such action would affect not only people outside the protectionist country but also those inside the country.

Equitable access to a vaccine against a pandemic influenza virus is an ethical issue involving justice for all. It is also a prerequisite for the success of any pandemic strategy to safeguard global health. As the novel H1N1 A influenza outbreak has revealed, developing a vaccine to respond to an emerging pandemic strain is a difficult task. Manufacturing and distribution capacity reside at the heart of this challenge.

Although the World Health Organization, the Centers for Disease Control and Prevention and others have been working hard to develop candidate influenza strains for vaccine manufacturers in advance of the H1N1 A strain's likely return during this coming influenza season, it has taken longer then expected. Furthermore, once clinical lots of a vaccine have been produced, trials must be conducted to determine the concentration and number of required doses and to obtain preliminary safety data. Only then can manufacturers gear up production. As a result, an H1N1 vaccine may not be ready until November.

Even after production begins, the global shortage of manufacturing capacity for the influenza vaccine will hamper efforts to combat a pandemic, particularly because production of a vaccine against a pandemic strain will have to compete with production of the regular influenza vaccine for the annual influenza season. There are close to 7 billion people in the world, but we have the capacity to generate only $1-2$ billion doses of vaccine per year according to conservative estimates. The gap between global supply and demand is further exaggerated if individuals require 2 doses of vaccine (a priming and a boosting dose) to protect against a novel strain.

Even if existing manufacturing plants could increase production capacity, there would still be a distribution problem. As part of their pandemic preparedness, many industrialized countries, including Canada, have negotiated contracts with vaccine companies to supply the pandemic vaccine, once it has been developed. The Canadian Pandemic Influenza Plan prioritizes distribution of the vaccine, under the assumption that Canada's entire population would be vaccinated over a 4-month period. ${ }^{1}$ GlaxoSmithKline has announced that it has already received orders from several other industrialized countries aiming to stockpile an H1N1 A vaccine as a precautionary step. ${ }^{2}$

But where do these plans leave less developed countries who have no signed contracts or who do not have the finan- cial resources to secure vaccines? And how can a pandemic strategy succeed, given the speed and accessibility of global travel, unless we vaccinate people in all regions of the world?

More than a century ago, fire brigades would only come to the properties of people who had paid in advance for this service. Firefighting services became universal once it was learned that paying for your own fire protection was useless if the unprotected building next door caught fire. If individual countries or whole regions do not have access to pandemic influenza vaccine, then, like a fire, the pandemic influenza virus will continue to spread and evolve. Given that any new vaccine is unlikely to be $100 \%$ protective, some people who have been vaccinated in the fortunate countries with access to vaccine will still be at risk of infection from unprotected populations.

In the face of this threat, we need to ensure wide and equitable access to any pandemic influenza vaccine. In the short term, nations should join the World Health Organization's campaign that urges pharmaceutical companies to donate a minimum of $10 \%$ of their pandemic vaccine production to developing countries - or at least to offer the vaccine at a price that these countries can afford. As of May 20, 2009, 6 of the 30 major manufacturers had agreed to this plan; greater participation is needed. Canada can take a leadership role not only by supporting this private-sector initiative but also by reserving $10 \%$ of its own purchase for use in developing countries. These proposed contributions still won't be nearly enough to vaccinate the entire population of developing countries. Currently, these countries do not even have access to routine annual influenza vaccine. Providing even limited access to a pandemic influenza vaccine would be a big step forward. Just call it enlightened self-interest.

In the longer-term, Canada must help develop a global initiative to increase the international capacity to manufacture influenza vaccine and to achieve a worldwide agreement on vaccine distribution. Just consider it global firefighting.

\section{Noni MacDonald MD MSc}

Section Editor, Public Health, CMAJ

With the Editorial-Writing Team (Paul C. Hébert MD MHSc, Matthew B. Stanbrook MD PhD, Ken Flegel MDCM MSc, Amir Attaran LLB DPhil and Laura Eggertson BA)

Competing interests: See www.cmaj.ca/misc/edboard.shtml.

\section{REFERENCES}

1. Public Health Agency of Canada. The Canadian pandemic influenza plan for the Health Sector. Annex D: Preparing for the pandemic vaccine response [updated 2008 Sep. 5]. Ottawa (ON): The Agency; 2006. Available: www.phacaspc.gc.ca/cpip-pclcpi/ann-d-eng.php\#2 (accessed 2009 Jun. 11)

2. GlaxoSmithKline update: A (H1N1) influenza vaccine development. GlaxoSmithKline; 2009. Available: www.gsk.com/media/pressreleases/2009/2009 _pressrelease_10054.htm (accessed 2009 Jun. 11).

All editorial matter in CMAJ represents the opinions of the authors and not necessarily those of the Canadian Medical Association. 